\title{
Preoperative Embolization of Intracranial Meningiomas: Efficacy, Technical Considerations, and Complications
}

\author{
D.M.S. Raper, R.M. Starke, F. Henderson Jr, D. Ding, S. Simon, A.J. Evans, J.A. Jane Sr, and K.C. Liu
}

\begin{abstract}
BACKGROUND AND PURPOSE: Preoperative embolization for intracranial meningiomas offers potential advantages for safer and more effective surgery. However, this treatment strategy has not been examined in a large comparative series. The purpose of this study was to review our experience using preoperative embolization to understand the efficacy, technical considerations and complications of this technique.
\end{abstract}

MATERIALS AND METHODS: We performed a retrospective review of patients undergoing intracranial meningioma resection at our institution (March 2001 to December 2012). Comparisons were made between embolized and nonembolized patients, including patient and tumor characteristics, embolization method, operative blood loss, complications, and extent of resection. Logistic regression analyses were used to identify factors predictive of operative blood loss and extent of resection.

RESULTS: Preoperatively, 224 patients were referred for embolization, of which 177 received embolization. No complications were seen in $97.1 \%$. There were no significant differences in operative duration, extent of resection, or complications. Estimated blood loss was higher in the embolized group (410 versus $315 \mathrm{~mL}, P=.0074$ ), but history of embolization was not a predictor of blood loss in multivariate analysis. Independent predictors of blood loss included decreasing degree of tumor embolization ( $P=.037)$, skull base location $(P=.005)$, and male $\operatorname{sex}(P=.034)$. Embolization was not an independent predictor of gross total resection.

CONCLUSIONS: Preoperative embolization is a safe option for selected meningiomas. In our series, embolization did not alter the operative duration, complications, or degree of resection, but the degree of embolization was an independent predictor of decreased operative blood loss.

ABBREVIATIONS: $\mathrm{ACT}=$ activated clotting time; $\mathrm{ECA}=$ external carotid artery; $\mathrm{PVA}=$ polyvinyl alcohol

$\mathbf{P}$ reoperative embolization has been an option for adjunctive treatment of intracranial meningiomas for almost 4 decades, but it remains used in only a minority of cases. ${ }^{1}$ Meningiomas are commonly supplied by the middle meningeal, accessory meningeal, ascending pharyngeal, or occipital branches of the external carotid artery (ECA), which are easily accessible by selective mi-

Received October 28, 2013; accepted after revision January 14, 2014

From the Department of Neurosurgery (D.M.S.R., R.M.S., D.D., J.A.J., K.C.L.), Radiology (A.J.E.), and School of Medicine (F.H.), University of Virginia Health System, Charlottesville, Virginia; and Department of Neurosurgery (S.S.), Penn State Hershey, Milton S. Hershey Medical Center, Hershey, Pennsylvania.

Paper previously presented as a Neurosurgical Forum presentation at: Annual Meeting of the Congress of Neurological Surgeons, October 19-23, 2013; San Francisco, California.

Please address correspondence to Daniel Raper, MBBS, University of Virginia, Department of Neurosurgery, Box 800212, Charlottesville, VA 22908; e-mail: raper@virginia.edu

三 Indicates article with supplemental on-line table.

http://dx.doi.org/10.3174/ajnr.A3919 crocatheterization. ${ }^{2}$ Branches of the internal carotid artery and pial feeders supplying the tumor may also be embolized, ${ }^{3-6}$ though these vessels are typically more difficult to access and are associated with a higher risk of parenchymal infarct. In an attempt to change the tumor characteristics to increase the likelihood of a gross total resection and minimize operative morbidity, a variety of embolization materials have been used, including polyvinyl alcohol (PVA) particles, ${ }^{7,8}$ large-caliber microspheres, ${ }^{8,9}$ ethylene-vinyl alcohol (Onyx; Covidien, Irvine, California), ${ }^{10,11}$ detachable coils, ${ }^{12}$ fibrin glue ${ }^{13}$ and hyperosmolar mannitol. ${ }^{14}$ The potential advantages of preoperative embolization include decreased operative duration, reduced operative blood loss, and alteration of tumor consistency, all of which decrease the technical difficulty of surgical resection and increase the likelihood of achieving a more complete resection. Embolization likely causes histopathologic changes within the meningioma, including necrosis, ischemic changes, and microvascular fibrinoid changes. ${ }^{15}$ Hypoxia caused by disruption of tumoral blood supply also 
causes changes in protein expression consistent with angiogenesis and promotion of growth, ${ }^{16}$ along with cytologic changes, including infiltration of macrophages. ${ }^{17}$ The combination of these changes may make histologic examination of embolized meningiomas more difficult because they may histopathologically resemble higher grade tumors. ${ }^{15,18-20}$ Embolization also carries with it the risk of procedural complications, including large-vessel dissection, microcatheter fracture, and unintended arterial or venous occlusion resulting in hemorrhagic or ischemic infarct. ${ }^{1,7,21-28}$

Series of meningiomas that were preoperatively embolized have been recently published, ${ }^{7}$ but the operative findings and postoperative course for embolized tumors have not been compared with nonembolized tumors in a large modern series. In this study, we sought to review our outcomes following preoperative angiography, embolization when possible, and resection of intracranial meningiomas for the following objectives: 1) to assess the effect of preoperative embolization on operative time, surgical blood loss, and extent of resection; 2) to compare outcomes and complications between resection of embolized and nonembolized meningiomas; and 3) to determine predictors of objective utility of meningioma embolization.

\section{MATERIALS AND METHODS}

We performed a retrospective review of all patients treated at the University of Virginia Hospital between March 2001 and December 2012. All patients who underwent craniotomy for resection of meningiomas were included in the study. Five patients were excluded due to incomplete records $(n=2)$, treatment with radiosurgery only $(n=1)$, or final pathology other than meningioma $(n=2)$. Inpatient and outpatient medical charts and imaging were reviewed for patient characteristics, pathologic details, intraprocedural and intraoperative findings, complications, and outcomes. Operative notes were reviewed for any comments made by the surgeon as to the ease or difficulty of the resection. The study was approved by the local institutional review board.

Maximal tumor diameter was measured on preoperative imaging studies and taken as the largest measurement in either the coronal, axial, or sagittal plane. Tumors were categorized according to location, and previous treatments were noted. Embolization characteristics, including embolized vessel, method of embolization, estimated percentage of tumor devascularization, and procedure-related complications, were noted. The extent of surgical resection, operative blood loss, and operative time were recorded. In most cases, the extent of tumor resection was recorded in the operative notes, based on the operating surgeon's estimate at the time of surgery. In cases in which no estimate was made, the extent of resection was estimated by the primary author based on review of operative reports and pre- and postoperative imaging. "Gross total" resection was defined as excision without visual residual tumor and lack of residual tumor on postoperative imaging; "sub-total" resection was defined as either residual tumor at operation $\leq 10 \%$ of the total tumor volume or signs of residual tumor on postoperative imaging; "partial" resection included resection of $<90 \%$ of tumor by report or postoperative imaging. Postoperative treatments and perioperative complications were also analyzed by the treatment group.

\section{Patient Selection}

Selection of patients for preoperative angiography was made on an individualized patient basis based on the treating neurosurgeon's preference and practice. Embolization was performed after assessment of diagnostic images by the treating interventional radiologist. Selection of patients for preoperative embolization was not formalized as an institutional protocol. Nevertheless, the following principles were generally followed in selection of patients for preoperative embolization: patients with meningiomas located at the sphenoid wing, convexity, or parasagittal locations; or those with meningiomas with imaging characteristics indicative of hypervascularization.

\section{Embolization Procedure}

All imaging was performed by using high-resolution biplane digital subtraction angiography, with steroid coverage. Using a $5 \mathrm{~F}$ micropuncture set, we punctured and cannulated the right common femoral artery and placed a $5 \mathrm{~F}$ arterial sheath over a guidewire. The sheath was attached to a continuous heparinized saline flush. Intravenous heparin was intermittently administered throughout the procedure, monitored with serial activated clotting time (ACT) measurements, with the ACT maintained at $250-300$. The heparin was not reversed following the procedure. Selective catheterization of cerebral arteries, including internal carotids, external carotids, and posterior circulation, was performed. After we selected appropriate vessels for embolization, a microcatheter (most commonly, Echelon 10; Covidien) was advanced to the target vessel and embolization was performed. Embolization materials included PVA, 150- to 250- $\mu$ m particles; Gelfoam (Pfizer, New York, New York); and/or coil embolization by using a variety of detachable coils. Closure was achieved with Angio-Seal (St. Jude Medical, Minnetonka, Minnesota), when possible, or manual compression. In most cases, an estimate of the percentage devascularization was included in the procedure report from the embolization, as estimated by the treating interventionalist. In cases in which the report did not clearly delineate a percentage devascularization, angiographic images and reports were reviewed and a percentage devascularization was assigned retrospectively by the primary author. In all cases, postprocedure angiographic images were examined and an estimate of the percentage devascularization of the tumor was made.

\section{Statistical Analysis}

Data are presented as mean and range for continuous variables and as frequency for categoric variables. Analysis was performed by using an unpaired $t$ test, $\chi^{2}$, or Fisher exact test as appropriate. Comparison of means among $\geq 3$ groups was performed with analysis of variance with Bonferroni post hoc analysis. Univariate analysis was used to test covariates predictive of the following dependent variables: greater than the median estimated surgical blood loss $(250 \mathrm{~mL})$ and gross total resection. Interaction and confounding was assessed through stratification and relevant expansion covariates. Factors predictive in univariate analysis $(P<$ $.20)$ were entered into a multivariate logistic regression analysis. ${ }^{29}$ $P$ values $\leq .05$ were considered statistically significant. Statistical analysis was performed with STATA 10.0 (StataCorp, College Station, Texas).

AJNR Am J Neuroradiol 35:1798-804 Sep 2014 www.ajnr.org 
Table 1: Patient and tumor characteristics

\begin{tabular}{|c|c|c|c|c|}
\hline & Total Cohort & Embo & No Embo & $P$ Value \\
\hline Total patients & 470 & 174 & 307 & - \\
\hline Total treated meningiomas & 504 & 177 & 327 & - \\
\hline Mean age (range) (yr) & $57(17-90)$ & $56(17-82)$ & $58(18-90)$ & .2988 \\
\hline Female (\%) & $336(71.5)$ & $116(66.7)$ & $223(72.6)$ & .185 \\
\hline Tumor location & & & & $<.001^{\mathrm{a}}$ \\
\hline Olfactory groove (\%) & $27(5.5)$ & $5(2.9)$ & $22(6.9)$ & \\
\hline Planum sphenoidale/tuberculum (\%) & $42(8.6)$ & $5(2.9)$ & $37(11.6)$ & \\
\hline Cavernous sinus $(\%)$ & $5(1.0)$ & 0 & $5(1.6)$ & \\
\hline Sphenoid wing (\%) & $66(13.5)$ & $31(18.0)$ & $35(11.0)$ & \\
\hline Suprasellar (\%) & $2(0.4)$ & 0 & $2(0.6)$ & \\
\hline Convexity (\%) & $187(38.2)$ & $65(37.8)$ & $122(38.2)$ & \\
\hline Parasagittal (\%) & 88 (18.0) & $41(23.8)$ & 47 (14.7) & \\
\hline Middle cranial fossa (\%) & $12(2.4)$ & $2(1.2)$ & $10(3.1)$ & \\
\hline Posterior fossa (\%) & $41(8.4)$ & 18 (10.5) & $24(7.5)$ & \\
\hline Intraosseous (\%) & $1(0.2)$ & $1(0.6)$ & 0 & \\
\hline Intraventricular (\%) & $9(1.8)$ & 0 & $9(2.8)$ & \\
\hline Cerebellopontine angle (\%) & $10(2.0)$ & $4(2.3)$ & $6(1.9)$ & \\
\hline Skull base location (\%) & $164(33.4)$ & $47(27.3)$ & $117(36.7)$ & $.036^{\mathrm{a}}$ \\
\hline Max. tumor diameter (mm) (range) & $38.7(5-89)$ & $45.6(16-89)$ & $34.9(5-89)$ & $<.001^{\mathrm{a}}$ \\
\hline Prior resection (\%) & 59 (11.9) & $11(6.4)$ & $48(15.0)$ & $.005^{\mathrm{a}}$ \\
\hline Prior radiosurgery (\%) & $35(7.0)$ & $11(6.3)$ & $24(7.5)$ & .626 \\
\hline Prior radiotherapy (\%) & $12(2.4)$ & $5(2.9)$ & $7(2.2)$ & .633 \\
\hline WHO grade & & & & .807 \\
\hline 1 & $344(74.8)$ & $121(75.2)$ & $223(74.6)$ & \\
\hline ॥ & $98(21.3)$ & $35(21.7)$ & $63(21.1)$ & \\
\hline III & $18(3.9)$ & $5(3.1)$ & $13(4.3)$ & \\
\hline Brain invasion & $108(21.4)$ & $42(23.7)$ & $56(17.1)$ & .773 \\
\hline
\end{tabular}

Note:-Embo indicates embolized group; -, not significant; No Embo, non-embolized group; Max., maximum; WHO, World Health Organization.

a Significant difference.

\section{RESULTS}

\section{Patient and Tumor Characteristics}

During the study period, surgical resection of intracranial meningiomas was performed in 470 patients (336 female, 134 male; Table 1). The mean age was 57 years (range, $17-90$ years). There were 504 meningiomas treated; 25 patients had multiple operations. Two hundred twenty-four patients were referred for preoperative embolization; in 47 cases, tumor anatomy was not suitable for embolization - either there was no tumor blush or the supply was primarily intradural with concern for en passage blood supply. Patient and tumor details are reported in Table 1 . The most common anatomic locations were convexity (38.2\%), parasagittal (18.0\%), sphenoid wing (13.5\%), and planum sphenoidale/tuberculum sella $(8.6 \%)$. The mean maximal tumor diameter was $38.7 \mathrm{~mm}$ (range, 5-89 mm). Prior resection had been performed in 59 cases (11.9\%); prior radiosurgery, in 35 cases $(7.0 \%)$; and prior radiation therapy, in 12 cases $(2.4 \%)$. There was a significant difference in baseline characteristics between tumors that did and did not receive embolization, including overall location, skull base location, tumor size, and history of resection (Table 1).

\section{Embolization Outcomes}

Patients were referred for preoperative embolization in 224 cases. Details of embolization in 177 patients who received preoperative angiography are shown in Table 2. PVA particles were used alone in 67 patients $(39 \%)$, together with Gelfoam pledgets in 75 patients (43.6\%), with coil embolization of the feeding vessel in 26 patients $(15.1 \%)$, with both Gelfoam and coiling in 1 patient $(0.6 \%), 8$ cases of embolization were not recorded. Coiling alone was used in 3 patients. Among the 177 embolized cases, the middle meningeal artery or branches were used most commonly for access (157 cases), followed by the occipital artery (21 cases), superficial temporal artery (14 cases), and internal maxillary artery (14 cases). Following embolization, $\geq 75 \%$ tumor devascularization was achieved in 107 cases, with 50\%-74\% embolization achieved in 27 cases, $25 \%$ $49 \%$ in 12 cases, and $<25 \%$ in 10 cases. The mean time from embolization to surgery was 1.6 days (median, 1 day; range, $0-31$ days).

\section{Embolization-Related Complications} Embolization-related complications occurred in 6 cases (2.9\%): There were 2 cases of dissection $(1.1 \%)$ and 1 case each of stroke, facial nerve palsy, scalp infarction, and iodine allergy. There were no hemorrhages related to preoperative embolization in our series. Due to the low number of complications from embolization, no statistical analysis of predictors of embolizationrelated complications was possible.

\section{Determinants of Operative Blood Loss}

Preoperative variables predictive of more than median blood loss (estimated blood loss of $>250 \mathrm{~mL}$ ) in univariate analysis included male sex $(P<.001)$, increasing tumor diameter $(P<.001)$, skull base location $(P<.001)$, increasing number of embolized vessels $(P=.001)$, decreasing percentage of tumor embolized $(P=.007)$, and history of embolization $(P=.046)$. Estimated blood loss at surgery was larger in the embolized group $(410 \mathrm{~mL})$ than in the nonembolized group ( $315 \mathrm{~mL}, P=.0074$ ) but was attributable to differences in baseline patient and tumor characteristics because a history of embolization was not a predictor of operative blood loss in multivariate analysis. Independent preoperative variables predictive in multivariate analysis included male sex $(\mathrm{OR}=3.22 ; 95 \% \mathrm{CI}, 1.09-9.47 ; P=.034)$, skull base location $(\mathrm{OR}=5.37 ; 95 \% \mathrm{CI}, 1.67-17.28 ; P=.005)$, and decreasing percentage embolization $(\mathrm{OR}=1.02 ; 95 \% \mathrm{CI}, 1.01-1.04 ; P=$ .037). These were unchanged when controlling for other variables, including history of embolization, increasing diameter, increasing number of vessels embolized, and World Health Organization grade.

\section{Surgical Outcomes}

Operative findings and outcomes are reported in Table 3. The mean operative time was 3 hours 53 minutes in the embolized group and 3 hours 39 minutes in the nonembolized group $(P=$ $.23)$. There were no significant differences in operative complications between tumors that did and did not receive embolization and no significant differences in the extent of resection $(P=.249)$. There was no significant difference in the proportion of patients 


\begin{tabular}{lc}
\hline & No. \\
\hline Referred for embolization & 224 \\
Successful embolization (\%) & $177(79.0)$ \\
Method of embolization & \\
PVA (\%) & $67(39.0)$ \\
PVA and Gelfoam (\%) & $75(43.6)$ \\
PVA and coil (\%) & $26(15.1)$ \\
Coil (\%) & $3(1.7)$ \\
PVA and Gelfoam and coil (\%) & $1(0.6)$ \\
Embolized vessel & \\
Middle meningeal & $157(67.4)$ \\
Occipital & $21(9.0)$ \\
Internal maxillary & $14(6.0)$ \\
Superficial temporal & $14(6.0)$ \\
Deep temporal branch & $13(5.6)$ \\
Ascending pharyngeal & $6(2.6)$ \\
Posterior auricular & $1(0.4)$ \\
Sphenopalatine & $3(1.3)$ \\
Meningohypophyseal trunk & $1(0.4)$ \\
Anterior cerebral artery branch & $1(0.4)$ \\
Middle cerebral artery branch & $1(0.4)$ \\
Vertebral artery branch & $1(0.4)$ \\
Tumor devascularization & \\
>75\% & $107(68.6)$ \\
$50 \%-74 \%$ & $27(17.3)$ \\
25\%-49\% & $12(7.7)$ \\
<25\% & $10(6.4)$ \\
Mean time from embolization to surgery & $1.6(0-31)$ \\
(days) (range) & \\
Complications & \\
Dissection & $2(1.1)$ \\
Facial nerve palsy & $1(0.6)$ \\
Stroke & $1(0.6)$ \\
Scalp infarction & $1(0.6)$ \\
lodine allergy & $1(0.6)$ \\
\hline
\end{tabular}

who received postoperative radiation therapy between the groups, but the nonembolized group had a lower rate of postoperative radiosurgery ( $8.6 \%$ versus $14.1 \%, P=.042$ ). Tumor characteristics and operative outcomes were also analyzed by embolization method, the details of which are shown in On-line Tables 1 and 2. There were no significant differences in any parameters between embolization techniques, except for a trend toward a greater percentage of postoperative radiosurgery in the PVA and coil group compared with PVA alone or PVA and Gelfoam groups $(P=.051)$.

\section{Predictors of Gross Total Resection}

Variables predictive of gross total resection in univariate analysis included smaller diameter $(P<.001)$, location other than skull base $(P<.001)$, no prior gamma knife radiosurgery $(P<.001)$, lower estimated blood loss $(P=.001)$, and lower pathologic grade $(P=.001)$. Preoperative variables predictive in multivariate analysis included location other than the skull base $(\mathrm{OR}=2.50 ; 95 \%$ CI, 1.51-4.17; $P<.005)$, no prior gamma knife radiosurgery $(\mathrm{OR}=3.33 ; 95 \% \mathrm{CI}, 1.49-7.14 ; P=.003)$, and decreasing diameter $(\mathrm{OR}=1.03 ; 95 \% \mathrm{CI}, 1.02-1.04 ; P<.005)$. These were unchanged when controlling for other variables, including preoperative embolization, percentage embolization, prior resection, and brain invasion.
Table 3: Operative outcomes

\begin{tabular}{|c|c|c|c|}
\hline & Embolized & Nonembolized & $\begin{array}{c}P \\
\text { Value }\end{array}$ \\
\hline Operative time (min) & $3: 53(0: 55-10: 39)$ & $3: 39(0: 37-13: 35)$ & .2348 \\
\hline Estimated blood loss (mL) & $410(0-2700)$ & $315(0-2200)$ & $.0074^{\mathrm{a}}$ \\
\hline Extent of resection & & & .249 \\
\hline Gross total & $116(69.5)$ & $228(75.2)$ & \\
\hline Subtotal & $33(19.8)$ & $42(13.8)$ & \\
\hline Partial & $18(10.8)$ & $33(10.9)$ & \\
\hline \multicolumn{4}{|l|}{ Operative complications } \\
\hline Subdural hematoma & $3(1.7)$ & $4(1.2)$ & .6455 \\
\hline Cerebral infarction & $3(1.7)$ & $3(0.9)$ & .4274 \\
\hline $\mathrm{ICH} / \mathrm{IVH}$ & 0 & $5(1.5)$ & .1015 \\
\hline CSF leak & $1(0.6)$ & $3(0.9)$ & .7173 \\
\hline Pseudomeningocele & $2(1.1)$ & $1(0.3)$ & .2593 \\
\hline Hydrocephalus & $1(0.6)$ & $1(0.3)$ & .6129 \\
\hline Seizure & 0 & $6(1.8)$ & .0726 \\
\hline Infection & $4(2.2)$ & $6(1.8)$ & .7560 \\
\hline Cranial nerve deficit & $2(1.1)$ & $4(1.2)$ & .9204 \\
\hline DVT/PE & $4(2.2)$ & $6(1.8)$ & .7560 \\
\hline Perioperative mortality & $2(1.1)$ & $2(0.6)$ & .5413 \\
\hline Other & $1(0.5)$ & $1(0.3)$ & .7242 \\
\hline Total complications & $23(12.9)$ & $43(13.1)$ & .960 \\
\hline Postoperative radiotherapy (\%) & $8(4.8)$ & $20(6.3)$ & .500 \\
\hline Postoperative radiosurgery (\%) & $23(14.1)$ & $27(8.6)$ & $.042^{\mathrm{a}}$ \\
\hline
\end{tabular}

Note:- $\mathrm{ICH} / \mathrm{IVH}$ indicates intracerebral hemorrhage/intraventricular hemorrhage; DVT/PE, deep vein thrombosis/pulmonary embolism.

a Significant difference.

\section{DISCUSSION}

Preoperative embolization is a well-established adjuvant technique in the management of intracranial meningiomas. The theoretic advantages of embolization include devascularization of the tumor with subsequent decreased operative blood loss, increased ease of tumor visualization, improved safety especially when resecting tumors in eloquent areas, and potentially improved ability to gain Simpson grade I or II resection. ${ }^{1,2,7,30-34}$ However, these have not been evaluated in a comparative cohort series. The present report is a large comparative series reporting outcomes of surgery for intracranial meningiomas, evaluating the efficacy and complications of preoperative embolization, and identifying multivariate predictors of operative blood loss and gross total resection. In a cohort of 504 consecutive meningiomas treated at our institution during an 11-year period, preoperative embolization was performed in $44 \%$ of cases. Extent of resection and operative time were not significantly different between cases that received preoperative embolization and those that did not. The estimated blood loss was higher in those receiving embolization; this difference was primarily due to variances in patient and tumor characteristics. However, when other important factors were controlled for in multivariate analysis, increasing degree of tumor embolization was associated with decreased operative blood loss. This implies that tumors referred for embolization in our series were more likely to have a greater degree of operative blood loss, and a larger extent of preoperative devascularization resulted in decreased operative blood loss.

Embolization-related complications occurred in 6 cases $(2.9 \%)$ in our series. There were 2 cases of dissection, 1 of thromboembolic stroke, 1 of facial nerve palsy, 1 of scalp infarction, and 1 of iodine allergy requiring abortion of the procedure. This overall complication rate is comparable with that in other series in the literature. ${ }^{1,7,24,35}$ In a recent systematic review, the overall complication rate of preoperative embolization was $4.6 \%{ }^{1}$ Ischemic complications are more likely when the intracranial tumor supply 

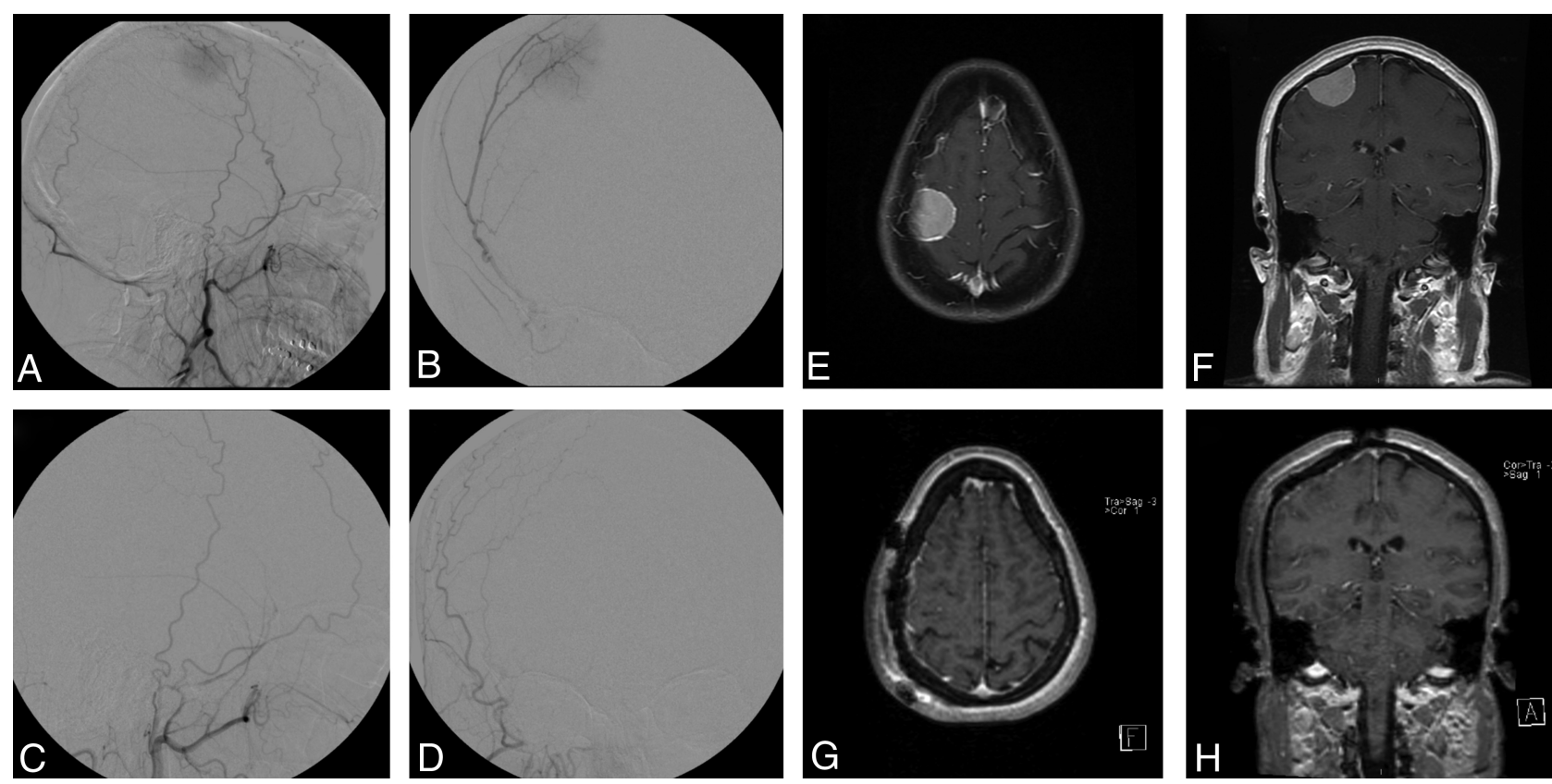

FIG 1. Right frontal meningioma, pre- and postembolization and resection. Pre-embolization right ECA injection demonstrates tumor blush from the middle meningeal artery ( $A$, lateral view; $B$, frontal view). Embolization was achieved with 150- to 250- $\mu$ m PVA particles. Postembolization right ECA injection reveals complete obliteration of tumor blush ( $C$, lateral view; $D$, frontal view). Tl-weighted MR imaging with gadolinium before embolization (E, axial view; $F$, coronal view). Tl-weighted MR imaging with gadolinium postresection (G, axial view; $H$, coronal view).

is targeted. ${ }^{21,23}$ For this reason, we do not routinely pursue embolization of the pial supply, which is often composed of fine branches from the middle or anterior cerebral arteries. There were no occurrences of hemorrhage in our series, which may be due to a relatively conservative embolization policy in which safety is prioritized over complete tumor devascularization in all cases. Hemorrhage is a potentially devastating complication of preoperative embolization and has been reported in up to $3 \%-6 \%$ of patients in some series. ${ }^{21,22,25,26,28}$ Hemorrhage may be more common after glue than particle embolization, ${ }^{1}$ secondary to reflux or distal embolization of liquid embolic material into physiologically important draining veins. Postembolization hemorrhage may also be related to alternation of pressure dynamics in highly vascular tumors or ischemic necrosis within the tumor. ${ }^{28}$ As a result, an increase in swelling may be observed following embolization, and care must be taken in tumors with significant pre-existing peritumoral edema or brain shift. ${ }^{36}$ Other important complications of embolization are related to the anatomic location of the target. Monocular blindness may occur as a result of inadvertent occlusion of ECA-to-ophthalmic artery anastomoses during embolization of anterior skull base tumors supplied by ethmoidal branches of the ophthalmic artery. ${ }^{27}$ Transient neurologic deficit has been reported in up to $12.6 \%$ of embolization procedures for skull base meningiomas, with up to $9 \%$ of patients experiencing a permanent deficit. ${ }^{27}$

Despite these limitations, there is evidence that preoperative embolization may be helpful in certain circumstances. Preoperative embolization has been associated with lower intraoperative blood loss and lower transfusion requirements, in previous small single-institution studies. ${ }^{32,33}$ Tumor shrinkage and apparent stabilization of growth has been reported after embolization, even without subsequent surgical resection. ${ }^{22,30,31}$ The technique has been used for lesions in all intracranial locations, including the skull base (Fig 1). ${ }^{5}$ Although embolization often makes a subjective difference to the presumed difficulty and duration of a case to the operating surgeon, it may be difficult to demonstrate objective differences in surgical outcomes and operative duration. ${ }^{32}$ For example, embolization that leads to a bloodless field during surgery for a tumor in an eloquent location may provide a subjective difference in tumor removal but may not have a significant overall effect on the surgical complications and outcomes. Additionally, difference may be difficult to quantify because particular cases that are selected for embolization are often larger and more complex lesions. Conventional angiography, with or without embolization, is not an absolute requirement for achieving Simpson grade I or II resections but may be helpful in mapping the intracranial vessels that are involved with or displaced by the tumor, thus assisting in surgical planning. Angiography may also reveal the presence of dural sinus occlusion. ${ }^{2}$ A meticulous surgical technique may allow early identification and devascularization of the meningioma, but tumor vessels on the far side of the lesion that are not immediately apparent can be delineated with angiography.

On the basis of our analysis of 470 patients with meningiomas treated at our institution during the past decade, we recommend consideration for preoperative angiography and embolization in the following situations:

1) Tumors $>3-4 \mathrm{~cm}$ in diameter, with at least $50 \%$ of the supply to the tumor originating from accessible branches of the $\mathrm{ECA}^{37}$

2) Tumors that appear hypervascular or appear to have a deepseated vascular supply difficult to surgically access based on noninvasive neuroimaging 
3) Tumors in eloquent areas

4) Tumors without extensive calcification, except in certain circumstances (see below).

Any protocol for preoperative embolization should consider safety more highly than attempting to achieve a complete tumor devascularization. We routinely use the following strategies to minimize complications and ensure the safety of embolization procedures. Each embolization is preceded by selective angiography of the ECA and ICAs bilaterally, as well as the vertebral arteries when appropriate. In particular, careful study of the middle meningeal artery drainage is performed before embolization to exclude meningolacrimal artery connection to the ophthalmic artery. ${ }^{5}$ Particles of $<150 \mu \mathrm{m}$ should be used with great caution, especially in branches of the middle meningeal artery that may contribute supply to the cranial nerves. Although there are no definitive anatomic-location criteria for selecting candidates for embolization, convexity meningiomas that have multidirectional blood supply and appear hypervascular are optimal embolization candidates. ${ }^{1}$ Tuberculum or olfactory groove meningiomas are less optimal candidates for embolization because these tumors are often fed by ethmoidal vessels, which are difficult to embolize without jeopardizing the vascular supply of the eye. ${ }^{5}$ Some tumors with extensive calcification are difficult to completely resect due to problems in stemming intraoperative bleeding, and embolization may be helpful in these cases even though calcification can also make successful preoperative exclusion of tumor blood supply more challenging.

The mean time from embolization to surgery was 1.6 days in our series, with most patients being embolized the day before resection. Although this is a common and practical application of preoperative embolization, because patients who have been treated in this manner usually require overnight observation in the hospital, some studies have suggested that delaying surgery for up to 7-9 days after embolization may allow time for maximal tumor softening and minimize blood loss. ${ }^{33,34,37,38}$ Other series have reported no difference in transfusion requirements between patients treated before or after 24 hours from embolization, ${ }^{39}$ and still others report a trend toward increasing operative transfusion requirements with longer delay between embolization and resection. ${ }^{7}$ The histopathologic findings of necrosis and enlarged nuclei, commonly found in meningiomas that have been embolized, may be confused with more aggressive and higher grade lesions. ${ }^{18}$ Most important, these findings increase with increasing time between embolization and surgery and may confound definitive histologic diagnosis in those institutions that routinely delay surgery after embolization for 5 days or longer.

There are some important limitations in our study that should be recognized. There were significant differences between the cohorts in our study. Patients in the embolized group had a higher proportion of sphenoid wing, parasagittal, and posterior fossa meningiomas; had a higher mean maximal tumor diameter; and were less likely to have undergone prior resection. Both skull base location and tumor diameter were found to be multivariate predictors of a more limited extent of resection, and skull base location was found to be a predictor of larger estimated blood loss in multivariate analysis. These differences likely reflect selection bias among the treated population as outlined above. The proportion of patients in whom embolization was not possible is consistent with other series. Reasons for failure to embolize a meningioma include dangerous intracranial supply with en passage supply to eloquent brain, inaccessible tumoral feeders, and reflux of embolization material from the superselective microcatheter into physiologic branches. ${ }^{24}$

\section{CONCLUSIONS}

Preoperative embolization continues to be a valuable adjunct to surgical resection for selected intracranial meningiomas. In our series, embolization did not alter the operative duration, complications, or degree of resection, but the degree of embolization was an independent predictor of decreased operative blood loss. The benefits of preoperative embolization appear to be similar to previously reported series, despite a shorter interval between embolization and surgery. Embolization should be considered on a case-by-case basis depending on imaging characteristics, anatomic location, and patient-specific factors.

Disclosures: Fraser Henderson Jr.—I have been salaried part-time for several years by the Metropolitan Neurosurgery Group in Bethesda, Maryland, for administrative assistance and office policy research. There is no relationship, financial or otherwise, between that job and my participation in the submitted manuscript, which is through my school in Virginia. Furthermore, that practice does not perform any endovascular work, nor do they treat many intracranial meningiomas. Avery J. Evans-UNRELATED: Consultancy: Stryker, Covidien, Grants/Grants Pending: Stryker, ${ }^{*}$ Payment for Lectures (including service on Speakers Bureaus): Stryker, Royalties: Cook, Payment for Development of Educational Presentations: Stryker. *Money paid to the institution.

\section{REFERENCES}

1. Shah AH, Patel N, Raper DM, et al. The role of preoperative embolization for intracranial meningiomas. J Neurosurg 2013;119: 364-72

2. Dowd CF, Halbach VV, Higashida RT. Meningiomas: the role of preoperative angiography and embolization. Neurosurg Focus 2003;15:E10

3. Hirohata M, Abe T, Morimitsu H, et al. Preoperative selective internal carotid artery dural branch embolization for petroclival meningiomas. Neuroradiology 2003;45:656-60

4. Kaji T, Hama Y, Iwasaki Y, et al. Preoperative embolization of meningiomas with pial supply: successful treatment of two cases. Surg Neurol 1999;52:270-73

5. Waldron JS, Sughrue ME, Hetts SW, et al. Embolization of skull base meningiomas and feeding vessels arising from the internal carotid circulation. Neurosurgery 2011;68:162-69

6. Yoon YS, Ahn JY, Chang JH, et al. Pre-operative embolization of internal carotid artery branches and pial vessels in hypervascular brain tumors. Acta Neurochir (Wien) 2008;150:447-52, discussion 452

7. Borg A, Ekanayake J, Mair R, et al. Preoperative particle and glue embolization of meningiomas: indications, results and lessons learned from 117 consecutive patients. Neurosurgery 2013;73(2 Suppl Operative):244-51; discussion 252

8. Sluzewski M, van Rooij WJ, Lohle PN, et al. Embolization of meningiomas: comparison of safety between calibrated microspheres and polyvinyl-alcohol particles as embolic agents. AJNR Am J Neuroradiol 2013;34:727-29

9. Rodiek SO, Stolzle A, Lumenta CB. Preoperative embolization of intracranial meningiomas with Embosphere microspheres. Minim Invasive Neurosurg 2004;47:299-305

10. Gore P, Theodore N, Brasiliense L, et al. The utility of Onyx for preoperative embolization of cranial and spinal tumors. Neurosurgery 2008;62:1204-12, discussion 1211-12

11. Shi ZS, Feng L, Jiang XB, et al. Therapeutic embolization of menin-

AJNR Am J Neuroradiol 35:1798-804 Sep 2014 www.ajnr.org

1803 
giomas with Onyx for delayed surgical resection. Surg Neurol 2008; 70:478-81

12. Kusaka N, Tamiya T, Sugiu K, et al. Combined use of TruFill DCS detachable coil system and Guglielmi detachable coil for embolization of meningioma fed by branches of the cavernous internal carotid artery. Neurol Med Chir (Tokyo) 2007;47:29-31

13. Probst EN, Grzyska U, Westphal M, et al. Preoperative embolization of intracranial meningiomas with a fibrin glue preparation. AJNR Am J Neuroradiol 1999;20:1695-702

14. Feng L, Kienitz BA, Matsumoto C, et al. Feasibility of using hyperosmolar mannitol as a liquid tumor embolization agent. $A J N R$ Am J Neuroradiol 2005;26:1405-12

15. Ng HK, Poon WS, Goh K, et al. Histopathology of post-embolized meningiomas. Am J Surg Pathol 1996;20:1224-30

16. Jensen RL, Soleau S, Bhayani MK, et al. Expression of hypoxia inducible factor-1 alpha and correlation with preoperative embolization of meningiomas. J Neurosurg 2002;97:658-67

17. Jiménez-Heffernan JA, Corbacho C, Canizal JM, et al. Cytological changes induced by embolization in meningiomas. Cytopathology 2012;23:57-60

18. Barresi V, Branca G, Granata F, et al. Embolized meningiomas: risk of overgrading and neo-angiogenesis. J Neurooncol 2013;113:207-19

19. Matsuda K, Takeuchi H, Yoshikazu A, et al. Atypical and ischemic features of embolized meningiomas. Brain Tumor Pathol 2012;29: $17-24$

20. Paulus W, Meizensberger J, Hofmann E, et al. Effect of embolization of meningioma on Ki-67 proliferation index. J Clin Pathol 1993;46: 876-77

21. Bendszus M, Monoranu CM, Schütz A, et al. Neurologic complications after particle embolization of intracranial meningiomas. AJNR Am J Neuroradiol 2005;26:1413-19

22. Carli DF, Sluzewski M, Beute GN, et al. Complications of particle embolization of meningiomas: frequency, risk factors, and outcome. AJNR Am J Neuroradiol 2010;31:152-54

23. Celedin S, Rabitsch E, Hausegger KA, et al. Accidental transtumoral microparticle embolization of eloquent brain areas in a case of large temporofrontal meningioma. Interv Neuroradiol 2008;14:339-43

24. Gruber A, Killer M, Mazal P, et al. Preoperative embolization of intracranial meningiomas: a 17-years single center experience. Minim Invasive Neurosurg 2000;43:18-29

25. Hayashi T, Shojima K, Utunomiya H, et al. Subarachnoid hemorrhage after preoperative embolization of a cystic meningioma. Surg Neurol 1987;27:295-300

26. Kallmes DF, Evans AJ, Kaptain GJ, et al. Hemorrhagic complications in embolization of a meningioma: case report and review of the literature. Neuroradiology 1997;39:877-80

27. Rosen CL, Ammerman JM, Sekhar LN, et al Outcome analysis of preoperative embolization in cranial base surgery. Acta Neurochir 2002;144:1157-64

28. Yu SC, Boet R, Wong GK, et al. Postembolization hemorrhage of a large and necrotic meningioma. AJNR Am J Neuroradiol 2004;25: 506-08

29. Altman DG. Practical Statistics for Medical Research. Boca Raton, Florida: Chapman \& Hall/CRC; 1999

30. Bendszus M, Martin-Schrade I, Warmuth-Metz M, et al. MR imaging — and MR spectroscopy — revealed changes in meningiomas for which embolization was performed without subsequent surgery. AJNR Am J Neuroradiol 2000;21:666-69

31. Bendszus M, Martin-Schrader I, Schlake HP, et al. Embolization of intracranial meningiomas without subsequent surgery. Neuroradiology 2003;45:451-55

32. Bendszus M, Rao G, Burger R, et al. Is there a benefit of preoperative meningioma embolization? Neurosurgery 2000;47:1306-12, discussion $1311-12$

33. Chun JY, McDermott MW, Lamborn KR, et al. Delayed surgical resection reduces intraoperative blood loss for embolized meningiomas. Neurosurgery 2002;50:1231-37, discussion 1235-57

34. Nania A, Granata F, Vinci S, et al. Necrosis score, surgical time, and transfused blood volume in patients treated with preoperative embolization of intracranial meningioma: analysis of a single-centre experience and a review of literature. Clin Neuroradiol 2014;24:29-36

35. Adler JR, Upton J, Wallman J, et al. Management and prevention of necrosis of the scalp after embolization and surgery for meningioma. Surg Neurol 1986;25:357-60

36. Engelhard HH. Progress in the diagnosis and treatment of patients with meningiomas. Part 1. Diagnostic imaging, preoperative embolization. Surg Neurol 2001;55:89-101

37. Kai Y, Hamada JI, Morioka M, et al. Clinical evaluation of cellulose porous beads for the therapeutic embolization of meningiomas. AJNR Am J Neuroradiol 2006;27:1146-50

38. Kai Y, Hamada JI, Morioka M, et al. Appropriate interval between embolization and surgery in patients with meningioma. AJNR Am J Neuroradiol 2002;23:139-42

39. Macpherson P. The value of pre-operative embolization of meningioma estimated subjectively and objectively. Neuroradiology 1991; 33:334-37 